\title{
METODOLOGIA CIENTÍFICA NO CURSO DE ADMINISTRAÇÃO: UMA NOVA PERSPECTIVA DIDÁTICA
}

\section{RESUMO}

É observado que, na graduação, a produção de uma pesquisa é um dos maiores desafios por parte dos alunos, pois é neste período da graduação que os alunos são inseridos ao centro da pesquisa, identificando-se, assim, com um dos maiores desafios dos graduandos. Por esta razão, este estudo apresenta a seguinte problematização: A didática apresentada pelo professor na disciplina de metodologia científica facilita a compreensão e assimilação do conteúdo pelo aluno? Como objetivo geral, expõe a verificação da eficácia dos métodos de ensino utilizados na disciplina de Metodologia Científica em um curso de Administração de uma Instituição de ensino superior, e que apresenta os seguintes objetivos específicos: explicitar o nível de conhecimento dos alunos do curso de administração em relação à pesquisa científica; expor os aspectos que dificultam o aprendizado dos alunos na disciplina de Metodologia; verificar a necessidade do uso de novos métodos didáticos a serem usados na disciplina de Metodologia Científica. A pesquisa é de natureza quantitativa e nela se aplicou um questionário como forma de responder à problemática e aos objetivos aqui propostos. Concluiu-se, por meio

Maria Aline Barbosa de Freitas

Bacharel em Administração Unichristus - Fortaleza-CEBR <malinebf@gmail.com>

Ana Vládia Cabral Sobral

Doutora em Ciências e Engenharia de Materiais - UFSC e professora da Unichristus - Fortaleza CE-BR < anavladias@gmail. com> da análise dos resultados, que a disciplina de Metodologia Científica contribui para o desenvolvimento dos trabalhos acadêmicos dos alunos; conclui-se, também, que a falta de prática no que diz respeito ao conteúdo abordado em sala é um dos aspectos que dificultam a compreensão e assimilação do conteúdo apresentado.

Palavras-chave: Administração. Didática. Metodologia Científica. Ensino. 


\section{INTRODUÇÃO}

Uma das formas de classificar os países em desenvolvidos ou avançados, ou de instituições de ensino em boas ou regulares é, inevitavelmente, a pesquisa científica (QUADROS, 2007). Devido a isso, neste aspecto, o ensino de graduação fica responsável por demonstrar técnicas de pesquisas e incentivar a produção científica.

No período da graduação, o acadêmico, independente do curso, é apresentado à disciplina de metodologia científica, que tem como objetivo expor as técnicas e despertar a consciência científica dos alunos.

Neste período da graduação, quando os alunos são inseridos no ambiente da pesquisa, é que se identifica um dos maiores desafios dos graduandos, pois muitas vezes o tema pesquisado é abordado no primeiro e no segundo ano de curso, encontrando-se dificuldade com a leitura e, consequentemente, com a escolha de um objeto de estudo.

Fica clara, então, a importância do professor de metodologia científica apresentar adequadamente os procedimentos para a elaboração de uma pesquisa, assim como encaminhar os alunos a despertar e quebrar seus paradigmas quanto à leitura e à produção correta dos trabalhos acadêmicos, pois no ensino médio muitos alunos sequer foram cobrados ou apresentados aos processos de construção científica da pesquisa.

Baseado no exposto, o presente estudo apresenta a seguinte problematização: A didática apresentada pelo professor na disciplina de metodologia científica facilita a compreensão e assimilação do conteúdo pelo aluno?

Esta pesquisa tem ainda como objetivo geral verificar a eficácia dos métodos de ensino utilizados na disciplina de metodo- logia científica em um curso de administração de uma instituição de ensino superior.

No sentido de ressaltar a importância destes métodos que auxiliam na compreensão do conteúdo da disciplina de metodologia científica, apresentam-se os seguintes objetivos específicos:

a) explicitar o nível de conhecimento dos alunos do curso de administração em relação à pesquisa científica;

b) expor os aspectos que dificultam o aprendizado dos alunos na disciplina de metodologia;

c) verificar a necessidade do uso de novos métodos didáticos a serem usados na disciplina de metodologia científica.

A relevância deste tema dá-se pelo fato da disciplina de metodologia científica ser vista pelo meio discente das universidades como uma das principais dificuldades encontradas por eles no decorrer do curso de administração. Desta forma, este estudo vem como forma de contribuir para pesquisas futuras acerca dos objetivos específicos expostos.

Portanto, o presente trabalho justifica-se em virtude da necessidade de estudo do tema em questão, tornando inevitável uma pesquisa mais aprofundada e beneficiando os docentes e demais pesquisadores com pesquisa acerca da importância da disciplina de metodologia científica no curso de administração.

Visando ao entendimento e compreensão do trabalho, o artigo está estruturado da seguinte forma: a parte 2 contém o referencial teórico que contextualiza sobre o tema pesquisado, seguido da metodologia aplicada na pesquisa, na parte 3 . Em seguida, na parte 4 , apresenta-se a análise de resultados e, por fim, a conclusão do estudo. 


\section{REFERENCIAL TEÓRICO}

\subsection{O PROCESSO ENSINO-APRENDI- ZAGEM NO ENSINO SUPERIOR}

As características e habilidades de um professor universitário se diferenciam de professores do ensino médio e fundamental. Isto porque, no ensino superior, o aluno possui maturidade de reflexão e discussão das questões envolvidas em sua área de estudo (BONAT, 2010).

Além das exigências legais, no que tange aos critérios requeridos pelo Ministério da Educação - MEC, para que se exerçam as atividades de professor universitário, há também critérios pessoais e técnicos a serem trabalhados pelo docente, visando a um melhor processo de ensino-aprendizagem (BONAT, 2010).

Baseado no descrito, cabe ao professor disseminar o conhecimento da forma mais prática e didática possível aos seus alunos, utilizando de suas características técnicas e pessoais para esta tarefa, desta maneira trazendo para a sala de aula suas experiências práticas aliadas aos seus conhecimentos técnicos e teóricos, visando à transmissão de conteúdo de forma interessante aos acadêmicos.

Por isso, Barbosa (2011) afirma que o processo de ensino tradicional consistia em o professor falar aquilo que sabia sobre determinado assunto, através de aulas expositivas e explicativas, esperando que o aluno reproduzisse o que lhe foi transmitido. Por muitos anos, este foi o processo de ensino apresentado, mais ele foi recebendo muitas críticas, dando origem a um novo conceito de ensino.

Este novo conceito de ensino consiste em criar condições de aprendizagem em que o mais importante é aprender a aprender, pois a aprendizagem é um processo de aquisição e assimilação de novas formas do saber, agir e pensar. Neste momento, o professor criará situações favoráveis ao aprendizado, utilizando de variedades de recursos e procedimentos de ensino (BARBOSA, 2011).

Em suma, a didática no ensino superior partirá de uma visão totalitarista do processo ensino-aprendizagem para uma perspectiva multidimensional da prática pedagógica que deverá ser trabalhada de forma articulada. Assim, as competências técnicas e práticas do professor se exigem mutuamente, não sendo possível a dissociação delas.

\subsection{O LÚDICO COMO INSTRUMENTO DE APRENDIZAGEM}

O principal objetivo da educação é formar pessoas criativas, capazes de modificar a maneira de viver com outras pessoas. Assim, o lúdico é o melhor meio para alcançar este objetivo (PESSOA, 2012).

Conforme Piaget (1982 apud WADSWORTH, 1984, p. 44):

\begin{abstract}
O jogo lúdico é formado por um conjunto linguístico que funciona dentro de um contexto social; possui um sistema de regras e se constitui de um objeto simbólico que designa também um fenômeno. Portanto, permite ao educando a identificação de um sistema de regras que permite uma estrutura sequencial que especifica a sua moralidade.
\end{abstract}

Assim, é possível verificar que o lúdico é um facilitador da aprendizagem; o problema na sua utilização está na falta de 
capacitação dos profissionais em adequar suas aulas, inserir algo que as deixe mais dinâmicas. Faz-se necessário uma reflexão sobre a utilização do lúdico em favor do aprendizado (PESSOA, 2012).

\subsection{MÉTODO E CIÊNCIA}

$\mathrm{O}$ processo de aprofundamento dos estudos, de reflexões e pesquisa exige do estudante uma postura nova em relação à atividade didática, tornando-se assim mais crítica e rigorosa (MAIA, 2008).

Assim, a utilização do método científico visa a descobrir a realidade dos fatos, através do uso de métodos. Desta forma, vê-se no mundo acadêmico que fazer ciência é importante, pois é por meio dela que se descobre, e o método representa uma forma de pensar para se chegar à natureza de um determinado problema, seja este problema para ser estudado, seja para ser explicado (MAIA, 2008).

\subsection{O ENSINO DE METODOLOGIA NA GRADUAÇÃO}

Por muitas vezes o ensino de metodologia científica é apresentado ao aluno em seus primeiros anos de curso. Devido a isso, observa-se pobreza nas produções científicas a qual advém do pouco conhecimento em relação ao assunto, nunca antes visto, $\mathrm{e}$ com a imaturidade intelectual e reflexiva do aluno com o assunto abordado na disciplina (SANTOS; REDYSON, 2008).

$\mathrm{O}$ ensino da disciplina de metodologia científica muitas vezes é cercado por perguntas as quais questionam o uso de tantas regras, detalhes, rigor nas formatações e digitação do texto. Estas exigências me- todológicas, por vezes, parecem estar presentes para privar o aluno de sua liberdade de escrever e pensar. (QUADROS, 2007).

O objetivo da metodologia científica é resgatar nos alunos a capacidade de pensar, significando passar de um nível espontâneo para um nível reflexivo. Desta maneira, aprende-se a pensar à medida que se realizam indagações sobre o ato de pensar (LIBANIO, 2001).

Segundo Quadros (2007), outra meta da metodologia científica está em ensinar a arte da leitura, da análise e interpretação de textos.

\begin{abstract}
Uma segunda meta a ser alcançada pela Metodologia Científica é aprender a arte da leitura, da análise e interpretação de textos. Vivemos o fenômeno do aluno-copista, vivemos a era do Ctrl C e Ctrl V, que reproduz em suas pesquisas e trabalhos acadêmicos aquilo que outros disseram, sem nenhum juízo de valor, de crítica ou apreciação. Reproduz sem ética sem dar o devido crédito intelectual e autoral (QUADROS, 2007, p. 93).
\end{abstract}

Desta maneira, o ensino da metodologia científica compreende não só a prática do pensamento reflexivo, mas também a capacidade de análise e interpretação dos textos lidos.

Em síntese, o ensino da metodologia científica não significa somente exigir o cumprimento de normas, mas ensinar e preparar o discente ao exercício da reflexão escrita, criando hábitos que o acompanharão por toda a vida, tais como o interesse pela leitura, o pensamento crítico e responsável, o exercício da ética, uma postura de humildade quanto ao pouco que se sabe em relação à infinidade existente de saberes. 


\section{METODOLOGIA DA PESQUISA}

\subsection{AMBIENTE DA PESQUISA}

A pesquisa foi realizada em uma instituição de ensino superior da cidade de Fortaleza - Ceará, com alunos que cursaram a disciplina de metodologia científica do curso de administração. Tais alunos encontram-se nos $3^{\circ}, 6^{\circ}, 7^{\circ}$ e $8^{\circ}$ semestres.

\subsection{NATUREZA DA PESQUISA}

Trata-se de uma pesquisa quantitativa, por atribuir uma frequência ao número de respostas do questionário aplicado. Assim, a pesquisa quantitativa centra-se na objetividade recorrendo à linguagem matemática para descrever ou solucionar um fenômeno em questão (FONSECA, 2002).

\subsection{TIPOLOGIA DA PESQUISA}

Quanto aos seus procedimentos, a pesquisa situa-se como bibliográfica pela utilização e seleção de material para fundamentar as discussões acerca do tema estudado e Survey por utilizar coleta de dados ao objeto estudado. (FONSECA, 2002).

Quanto aos objetivos, situa-se como pesquisa descritiva por utilizar de técnicas de coletas de dados como o questionário. Segundo Reis (2010), a pesquisa descritiva tem como objetivo estabelecer a inter-relação entre o fenômeno e a população (grupo social), sendo usada para desenvolver a pesquisa bibliográfica e documental.

\subsection{UNIVERSO E AMOSTRA}

A pesquisa foi aplicada a alunos de administração noturnos de uma Instituição de Ensino Superior (IES) particular de Fortaleza, alcançando-se um total de 272 alunos como população. Segundo Marconi e Lakatos (2002, p. 41), "população é o conjunto de seres animados ou inanimados que apresentam pelo menos uma característica em comum".

Para tanto, a amostra definiu-se em 30 pesquisados, sendo os alunos regularmente matriculados e cursando os respectivos semestres: $3^{\circ}, 6^{\circ}, 7^{\circ}$ e $8^{\circ}$. De acordo com Marconi e Lakatos (2002, p. 41), “amostra é uma porção ou parcela, convenientemente selecionada do universo (população)".

Como critério de seleção, os semestres $3^{\circ}, 6^{\circ}, 7^{\circ}$ e $8^{\circ}$ foram escolhidos pelo fato dos alunos cursarem disciplinas que tinham como pré-requisito a conclusão da matéria de metodologia e, por isso, estariam utilizando seus conhecimentos para produzir seus projetos e monografias, à exceção do $3^{\circ}$ semestre, que foi escolhido com base no fato de que os alunos já haviam cursado a disciplina de metodologia no semestre anterior e estariam aptos a responder às perguntas. Além disso, tais alunos já teriam feito pelo menos um trabalho científico.

Excluem-se os semestres $4^{\circ}$ e $5^{\circ}$ pelo fato dos alunos não cursarem nenhuma disciplina que necessitasse do conhecimento e prática adquiridos em metodologia científica para realização destas.

\subsection{COLETA DE DADOS E PERÍODO DA COLETA}

A coleta de dados compreendeu-se na aplicação de um questionário estrutu- 
rado, com 9 questões de múltipla escolha e uma questão aberta. Segundo Marconi e Lakatos (2002, p. 34), esta é a "etapa da pesquisa em que se inicia a aplicação dos instrumentos elaborados e das técnicas selecionadas, a fim de se efetuar a coleta dos dados previstos".

O questionário foi aplicado em sala de aula dos semestres citados anteriormente e disponibilizado de forma virtual para os respondentes. Foi aplicado no ano de 2013, no mês de março, ao público-alvo mencionado anteriormente.

\section{ANÁLISE DOS RESULTADOS}

A seguir serão apresentados os resultados obtidos com a aplicação do questionário. $\mathrm{O}$ Gráfico 1 mostra o semestre atual dos entrevistados:

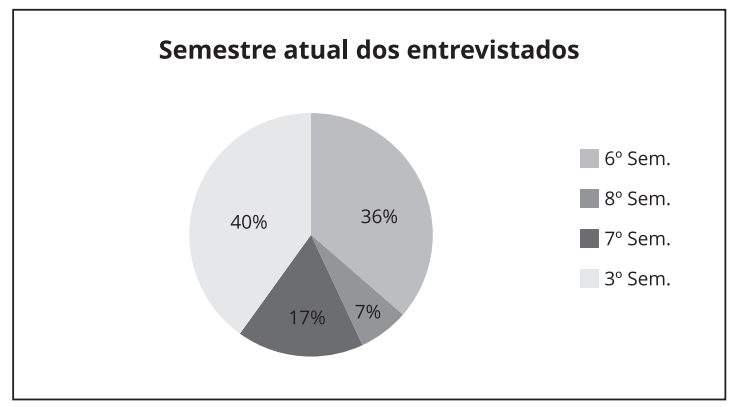

Figura 1 - Respondentes e seus semestres Fonte: elaborado pelas autoras (2013).

Como apresentado pela Figura 1, a maior participação quanto à aplicação do questionário foi dos alunos do $3^{\circ}$ semestre, com $40 \%$ da participação, seguida pelos alunos do $6^{\circ}$ semestre, com $36 \%$. Verificou-se que a pouca participação dos alunos do $7^{\circ}$ e $8^{\circ}$ semestres deu-se pelo fato de ambos não recordarem mais do tempo que cursaram a disciplina de metodologia. $\mathrm{Na}$ instituição de ensino pesquisada, assim como em outras instituições, a disciplina de me- todologia é vista logo nos primeiros anos de curso, conforme mencionado por Santos e Redyson (2008).

Com relação ao conhecimento dos discentes quanto à pesquisa, a Figura 2 mostra que $50 \%$ pouco conhecia sobre a estrutura da pesquisa nos moldes acadêmicos. Segundo Maia (2008), este fato se dá pela deficiência da formação básica desses alunos, pois neste período não é dada a devida importância sobre a elaboração de projetos como mensuração da capacidade crítica e ética dos alunos.

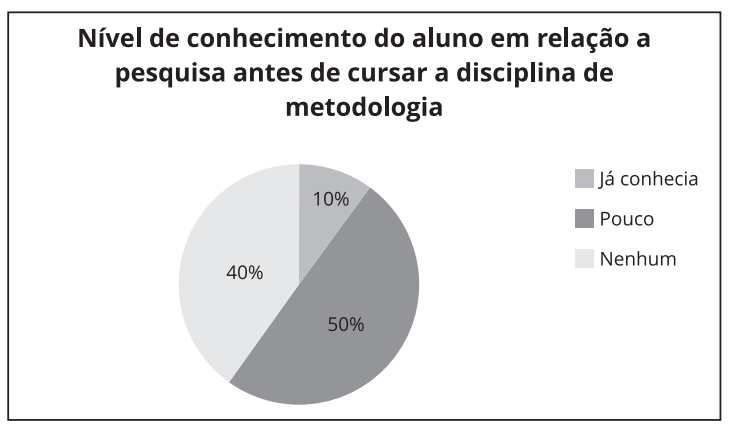

Figura 2 - Nível de conhecimento em relação à pesquisa científica

Fonte: Elaborado pelas autoras (2013).

$\mathrm{Na}$ questão 3 apresentada no questionário, foi solicitado do entrevistado que mencionasse três aspectos que dificultaram seu aprendizado e assimilação do conteúdo na disciplina de metodologia científica. Sendo assim, a somatória não condiz com o número de respondentes, pois os mesmos tinham uma questão aberta para citar três aspectos dificultadores de aprendizado. Nesta questão, foi realizada uma análise de conteúdo qualitativo, para verificar a frequência das palavras mais citadas pelos alunos. O quadro 1 mostra que a "prática" foi a palavra que obteve maior frequência. Desta forma, assim como mencionado por Bonat (2010, p.35), as aulas expositivas e narrati- 
vas tratam o aluno como um recipiente, no qual "o professor, detentor de todo o saber despeja os conteúdos".

\begin{tabular}{|l|c|}
\hline \multicolumn{1}{|c|}{ Características } & Frequencia \\
\hline Prática & 11 \\
\hline Didática & 10 \\
\hline Tempo & 7 \\
\hline Material & 1 \\
\hline Não responderam & 8 \\
\hline
\end{tabular}

Quadro 1 - Itens que dificultaram o aprendizado Fonte: elaborado pelas autoras (2013).

Na Figura 3, 77\% dos entrevistados concordam com o fato do professor ser pesquisador. Segundo Veiga (2007), a pesquisa torna o professor capaz de refletir sobre sua prática profissional, ajudando-o a aperfeiçoar sua prática docente de modo que o mesmo possa participar efetivamente do processo de emancipação das pessoas.

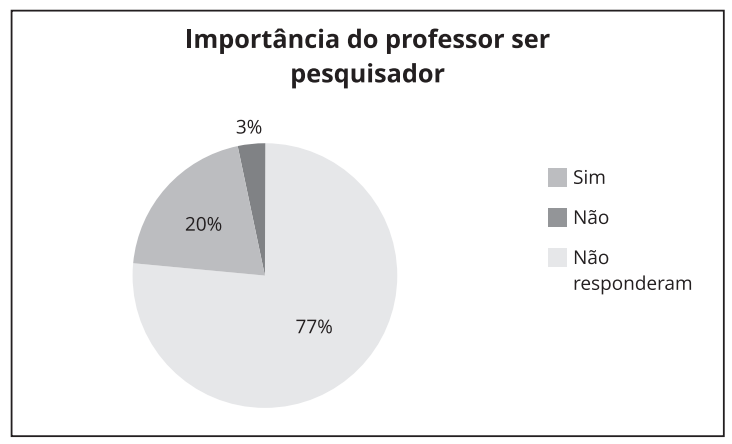

Figura 3 - A importância do professor-pesquisador Fonte: elaborado pelas autoras (2013).

Na Figura 4, 87\% dos discentes entrevistados concordam com aulas mais lúdicas, com auxílio de jogos, recursos tecnológicos, entre outros recursos que facilitem a assimilação do conteúdo, visto que a disciplina é tida como sendo muito teórica. Para Mercado (2002, p. 11), "no contexto de uma sociedade do conhecimento, a educação exige uma abordagem diferente em que o componente tecnológico não pode ser ignorado".

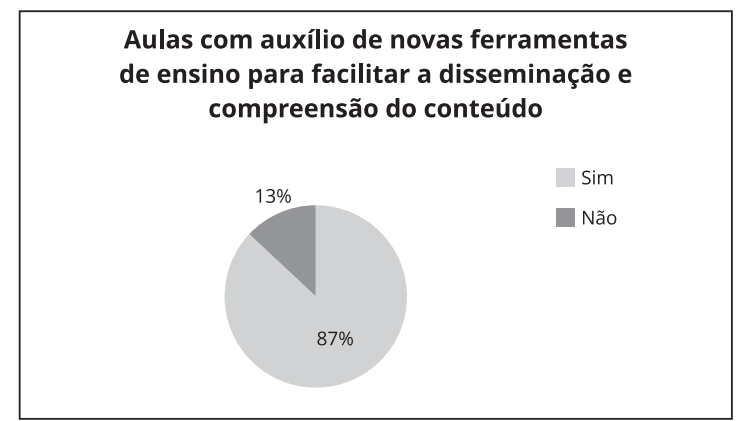

Figura 4 - Aulas com auxílio de novas ferramentas de ensino

Fonte: elaborado pelas autoras (2013).

A Figura 5 mostra que 93\% dos entrevistados concordam que aulas práticas ajudariam na absorção do conhecimento da disciplina de metodologia. Para Quadros (2007), não basta somente memorizar as normas da ABNT sem construção de sentidos, e sim é preciso compreender sua funcionalidade no que comporta o saber fazer.

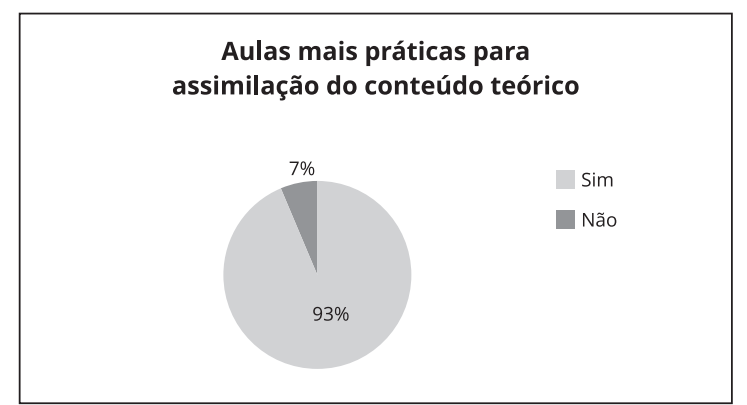

Figura 5 - Aulas práticas para assimilação do conteúdo teórico

Fonte: elaborado pelas autoras (2013).

Os entrevistados foram questionados quanto às dúvidas que possuíam antes de cursarem a disciplina, se as mesmas foram sanadas. Como mostrado na Figura 6, 
$60 \%$ dos alunos não tiveram suas dúvidas respondidas. Isto se dá pela pouca prática que os discentes possuem com as normas de construção de pesquisas (MAIA, 2008).

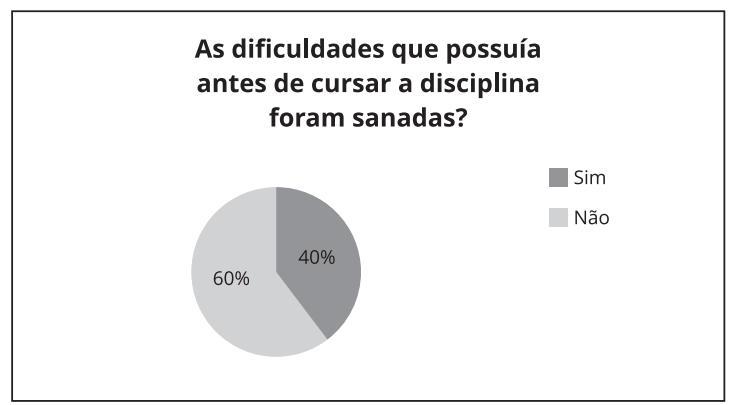

Figura 6 - Dificuldades que possuía antes de cursar a disciplina foram sanadas?

Fonte: elaborado pelas autoras (2013).

As questões 8 e 9 são apresentadas nas Figuras 7 e 8, respectivamente. Estas figuras $(77 \%$ e $43 \%$, respectivamente) mostram que os discentes não têm facilidade na construção de seus relatórios de estágios, monografias e artigos após a conclusão da disciplina de metodologia científica.

Segundo Maia (2008), a diversidade de regras e formatação dos textos científicos que parecem cercear a liberdade do aluno de escrever e pensar faz com que o estudo da metodologia científica seja raramente bem aceito pelos alunos, gerando a dificuldade de assimilação de conteúdo.

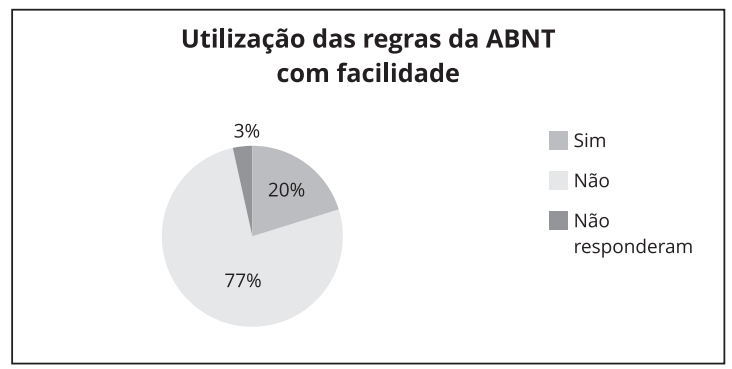

Figura 7 - Facilidade na utilização das regras da ABNT Fonte: elaborado pelas autoras (2013).

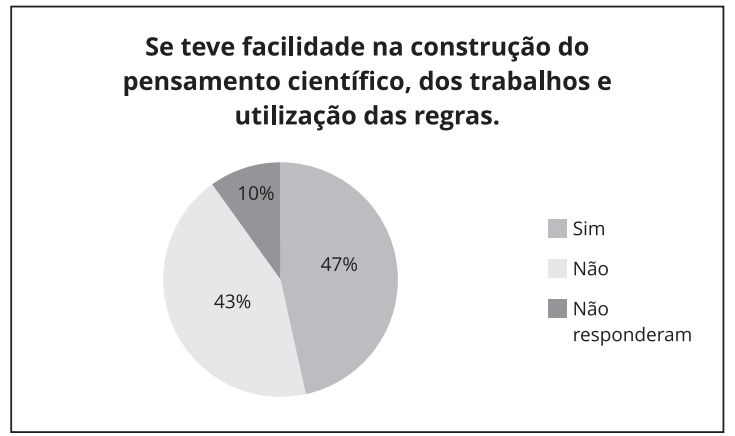

Figura 8 - Facilidades na construção do pensamento científico e dos trabalhos

Fonte: elaborado pelas autoras (2013).

A Figura 9 deixa claro que $33 \%$ dos entrevistados consideram o segundo semestre ideal para a abordagem do conteúdo da disciplina de metodologia. Assim, a dificuldade de aprendizado dos alunos quanto ao conteúdo abordado na disciplina de metodologia científica não está no semestre no qual essa disciplina é aplicada, mas sim nas técnicas de ensino apresentadas pelo professor da disciplina. Como evidenciado nas análises anteriormente expostas aqui nesta pesquisa.

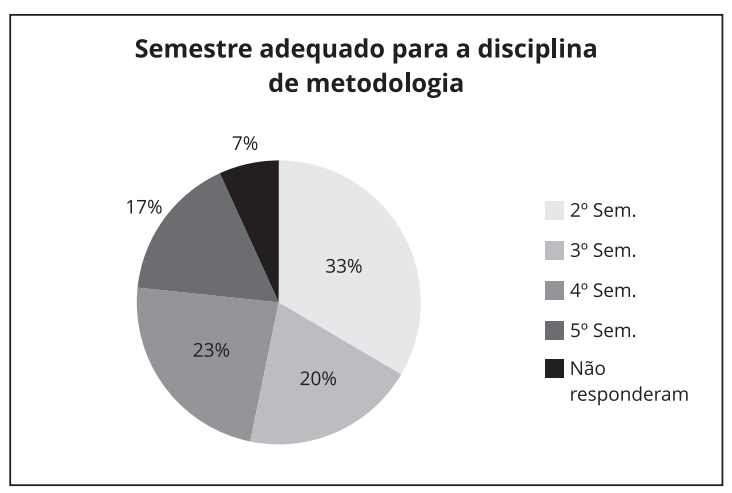

Figura 9 - Semestre ideal para disciplina de metodologia científica

Fonte: elaborado pelas autoras (2013). 


\section{CONCLUSÃO}

A problemática apresentada foi respondida no quadro 1 da análise de resultados, pois, com a pesquisa, ficou evidenciado que a falta de prática do assunto exposto na disciplina é o fator dificultador da compreensão e assimilação do conteúdo transmitido.

O objetivo geral da pesquisa foi atingido, ficando clara a importância de novos métodos de ensino a serem utilizados pelo professor da disciplina de metodologia científica. Estes novos métodos tendem a facilitar a compreensão dos alunos e prepará-los não só para a realização de trabalhos acadêmicos, mas para a construção de pensamento crítico e reflexivo, criando, assim, nos discentes, hábitos e posturas de si mesmo, do outro e do mundo que beneficia sua vida social, profissional, econômica e cultural.

A pesquisa também satisfez às respostas quanto aos objetivos específicos, ficando claras as seguintes conclusões:

a) na figura 2 da análise de resultados, mostra-se que $50 \%$ dos entrevistados pouco conheciam da pesquisa científica; já na figura 8 , mostra-se que $47 \%$ dos respondentes tiveram facilidade na construção de seus trabalhos, mostrando, assim, a contribuição da disciplina de metodologia, e revelando o nível de conhecimento dos alunos antes e depois da disciplina;

b) as figuras 4 e 5 respondem bem ao segundo e terceiro objetivos específicos aqui expostos. Assim como o quadro 1 , que apresenta que a prática nesta disciplina aliada a métodos de ensinos dinâmicos com auxílio de novas e variadas ferramentas de ensino contribuiriam melhor para a assimilação dos assuntos abordados na disciplina de metodologia científica.

Esta pesquisadora apresenta como sugestão de melhoria para futuras pesquisas a formulação de um questionamento mais objetivo quanto ao conhecimento dos respondentes após cursar a disciplina de metodologia científica.

Apresentam-se também neste tópico as limitações da pesquisadora neste estudo: o tempo, ou melhor, a falta de tempo para se dedicar mais à pesquisa e à aplicação do questionário em outros horários foi uma das principais limitações aqui encontradas.

Contudo, convém propor uma nova didática de ensino para facilitar a compreensão dos assuntos abordados na disciplina de metodologia, que se utilize de meios tecnológicos, jogos, aulas práticas que auxiliem nesta nova didática de ensino.

\section{SCIENTIFIC METHODOLOGY IN THE COURSE OF ADMINISTRATION: A NEW DIDACTIC PERSPECTIVE}

\section{SUMMARY}

It has been observed that, in order to accomplish Graduation, the elaboration of an undergraduate research is one of the major challenges on the part of the students, since it is in this Graduation period that the students come in contact with the centers of research, and meet one of the major challenges in the process of Graduation that is the elaboration of an essay paper based upon the researches they have carried out. On account of that, this study presents the following questioning: 
Does the teaching method applied by the professor of the discipline Scientific Methodology make the understanding and the assimilation of the contents easier for the students? On the whole, does it expose the verification of the effectiveness of the teaching methods used in the discipline of Scientific Methodology in the Course of Administration of a College Institution that claims to have the following specific objectives: to make explicit the level of knowledge of the students on the course of Administration in relation to scientific research; to expose the aspects that hinder the learning of the students in the discipline of Methodology; to check the necessity for the use of new teaching methods to be used in the discipline of Scientific Methodology. The research is quantitative in nature and it applied a questionnaire in order to respond to the questions and to comply with the objectives proposed here. It was concluded, by means of the analysis of the results, that the discipline of Scientific Methodology does contribute to the development of the students' academic work; it was also that the lack of practice in regard to the content as presented in the classroom is one of the aspects that hinder the understanding and the absorption of the contents presented.

Keywords: Administration. Didactics. Scientific methodology. Education.

\section{REFERÊNCIAS}

BARBOSA, Jane Rangel Alves. Didática do ensino superior. 2. ed. Curitiba: IESDE, 2011.
BONAT, Debora. Didática do ensino superior. 3. ed. Curitiba: IESDE, 2010.

FONSECA, João José Saraiva de. Metodologia da pesquisa científica. Fortaleza: UECE, 2002.

LIBÂNIO, João Batista. Introdução à vida intelectual. 2. ed. São Paulo: Loyola, 2001.

MAIA, Rosane Tolentino. A importância da disciplina de metodologia científica no desenvolvimento de produções acadêmicas de qualidade no nível superior. Revista Urutágua: revista acadêmica multidisciplinar, Maringá- PR, n.14, p.01-08, mar. 2008. Disponível em: $<$ http://www.urutagua.uem.br/014/14maia.htm>. Acesso em: 23 mar. 2013.

MARCONI, Marina de Andrade; LAKATOS, Eva Maria. Técnicas de pesquisa: planejamento e execução de pesquisas, amostragens e técnicas de pesquisas, elaboração, análise e interpretação de dados. 5. ed. São Paulo: Atlas, 2002.

MERCADO, Luís Paulo Leopoldo (Org.). Novas tecnologias na educação: reflexões sobre a prática. Maceió: EDUFAL, 2002.

PESSOA, Marilia de Abreu. O lúdico enquanto ferramenta no processo ensino-aprendizagem. 2012. Monografia (Pós-graduação em educação física escolar) - Universidade Federal do Ceará, Fortaleza, 2012. 
QUADROS, Marivete Basseto de. A importância da disciplina de metodologia da pesquisa científica na universidade. In: $\mathrm{CON}$ GRESSO DE EDUCAÇÃO DO NORTE PIONEIRO - EDUCAÇÃO E INTERDISCIPLINARIDADE, 7., 2007, Jacarezinho. Anais... Jacarezinho: FAFIJA, 2007. p. 8898. . Disponível em: $<$ http://formacaodigital.com.br/wp-content/uploads/2009/08/ QUADROSan2007.pdf>. Acesso em: 23 mar. 2013.

REIS, Linda G. Produção de monografia da teoria à prática: o método educar pela pesquisa (MEP). 3. ed. Brasília: Senac, 2010.

SANTOS, Ozilma Freire dos; REDYSON, Deyve. . A importância epistemológica da metodologia de pesquisa nas ciências sociais. In: ENCONTRO DE INICIAÇÃO A DOCENCIA, 11., 2008, João Pessoa. Anais... João Pessoa: UFPB-PRG, 2008. Disponível em:<http://www.prac.ufpb.br/ anais/xenex_xienid/xi_enid/monitoriapet/ ANAIS/Area4/4CCAEDHMT01-P.pdf>. Acesso em: 23 mar. 2013.

VEIGA, Ilma Passos Alencastro (Org.). Lições de Didática. 2. ed. Campinas: Papirus, 2007.

WADSWORTH, Barry. Jean Piaget para o professor da pré-escola e $\mathbf{1}^{\mathbf{0}}$ grau. São Paulo: Pioneira, 1984.

\section{BIBLIOGRAFIA COMPLEMENTAR}

RODRIGUES, Rui Martinho. Pesquisa acadêmica: como facilitar o processo de preparação e suas etapas. São Paulo: Atlas, 2007. 


\section{A MOTIVAÇÃO NO ENSINO SUPERIOR: UM ESTUDO COM ALUNOS DOS CURSOS DE ADMINISTRAÇÃO E DIREITO}

\section{RESUMO}

Thalita Lima Ferreira da

Silva

Graduanda em Administração

- Unichristus- Fortaleza-CE-

BR <thalitalimaf@gmail.

com $>$

Iago Pessoa

Mascarenhas

Graduando em

Administração - Unichristus

- Fortaleza-CE-BR <iago.

pessoa@yahoo.com.br>

Caio Pinheiro de

Medeiros

Graduando em

Administração - Unichristus

- Fortaleza-CE-BR < caio_

pm1@hotmail.com>

Ellen Campos Sousa

Mestre em Administração -

Unichristus - Fortaleza-CE-

BR <contato.ellencampos@

gmail.com $>$
A motivação do aluno é um dos componentes essenciais para a aprendizagem. De acordo com a teoria de autodeterminação, essa motivação pode ser intrínseca e extrínseca e a ausência dela gera a desmotivação. O objetivo deste trabalho é: identificar a motivação para aprendizagem dos discentes de Administração e Direito de um Centro Universitário em Fortaleza-Ce e as possíveis diferenças em razão dos cursos, turnos e semestres dos alunos. Para se chegar ao resultado, realizou-se uma pesquisa quantitativa, tendo como instrumento de pesquisa um questionário adaptado e validado para o Ensino Superior por Sobral (2003). A escala utilizada trabalha os constructos de motivação intrínseca, extrínseca e desmotivação. A amostra resultou em 105 questionários válidos. A análise dos dados mostrou que os alunos dos dois cursos estão motivados por fatores intrínsecos e extrínsecos, havendo diferença entre os turnos no curso de Administração.

Palavras-chave: Motivação. Ensino Superior. Administração. Direito.

\section{INTRODUÇÃO}

Um curso de ensino superior é cada vez mais procurado, visto que cada vez mais o mercado de trabalho exige qualificação profissional. Atualmente, essa demanda vem, em grande parte, sendo atendida pelas instituições privadas, mas nem sempre foi assim. Foi a partir das mudanças que ocorreram na educação superior do Brasil na década de 1990 (com a promulgação da Lei de Diretrizes e Base da Educação, em 1996) que se mudou a relação entre o Estado e a educação, promovendo uma desburocratização para ofertas 
de vagas no ensino superior (MATHIAS, 2004). Com o incentivo à expansão do setor para organizações privadas, desde então houve um crescimento enfatizado na quantidade de cursos superiores em todo o país.

$O$ ingresso em uma formação superior no Brasil tem suas dificuldades que partem desde a escolha do curso à sua conclusão. Entretanto, após ingressarem no curso, muitos alunos acabam evadindo. De acordo com Silva Filho et al. (2007), as perdas relacionadas à evasão são grandes no setor privado, pois além da perda de receitas, a evasão ocasiona a ociosidade dos recursos humanos e ainda de equipamentos e do espaço físico. Entende-se que um dos principais fatores que podem levar à evasão é a desmotivação do aluno para com o curso ou a instituição.

A motivação pessoal é reconhecidamente um fator de destaque no estudo do comportamento, podendo ela advir de estímulos externos ou internos. Desta forma, acredita-se que a motivação do aluno é um dos componentes essenciais para a aprendizagem (GUIMARÃES; BORUCHOVIT$\mathrm{CH}, 2004)$ e, consequentemente, um fator diretamente relacionado à permanência do aluno no curso.

Diversos estudos foram realizados para identificar a motivação dos alunos diante do serviço prestado em forma de ensino (JOLY; PRATES, 2011; SOBRAL, 2003). Entretanto, este não é um assunto finalizado, visto que cada instituição e cada aluno possuem suas peculiaridades. Desta forma, percebe-se a importância da contínua realização de pesquisas para acompanhar a motivação geral do aluno, a fim de concluir os estudos e não evadir. Entende-se que este estudo tem grande relevância para a instituição, sendo este um valioso instrumento para a gestão da universidade.
A partir deste entendimento, este estudo traz o seguinte objetivo geral: identificar a motivação para aprendizagem dos discentes de Administração e Direito de um Centro Universitário em Fortaleza-Ce e as possíveis diferenças em razão dos cursos, turnos e semestres dos alunos.

Desta forma, apresentam-se os seguintes objetivos específicos: identificar os percentuais de motivações intrínseca e extrínseca e de desmotivação dos alunos dos cursos de Administração e Direito; comparar as médias de motivações intrínseca e extrínseca e de desmotivação dos alunos dos cursos de Administração e Direito em relação ao turno que cursam; comparar as médias de motivações intrínseca e extrínseca e de desmotivação dos alunos dos cursos de Administração e Direito em relação ao semestre que cursam; apresentar o grau de motivação global para prosseguir nos estudos e se formar dos alunos dos cursos de Administração e Direito.

Para atender aos objetivos propostos, foi realizada uma pesquisa quantitativa com estudantes dos cursos de Administração e Direito de um Centro Universitário em Fortaleza/CE. A escala utilizada foi adaptada e validada para o segmento do ensino superior por Sobral (2003). Os dados foram trabalhados com auxílio do software SPSS (Statistical Package for the Social Sciences) versão 19.0, módulos de estatística descritiva, Análise de Médias e Análise de Variância (ANOVA).

\section{MOTIVAÇÃO NO ENSINO SUPERIOR}

Compreender a motivação humana tem sido um desafio. De acordo com Almeida (2012), várias investigações têm sido rea- 
lizadas e diversas teorias têm tentado explicar o funcionamento desta força que leva as pessoas a agirem em prol do alcance de objetivos. A motivação é um dos determinantes principais de rendimento individual. Outras variáveis, como o esforço, as capacidades individuais, o suporte social e a experiência prévia também influenciam o rendimento, podendo haver também variáveis de caracterização pessoal, percepção do aluno acerca do curso, o objetivo de concluir os estudos e atuar na área de formação, o desempenho alegado e a visualização do esforço do aluno (ALMEIDA, 2012).

A palavra motivação provém do latim movere, cujo supino motum e o substantivo motivum, do latim tardio, deram origem ao termo, semanticamente aproximado, motivo. Assim, a palavra motivação é derivada do verbo motivar e refere-se ao motivo, àquilo que move a pessoa, que a faz entrar em ação e a impulsiona para algum objetivo. Também é entendida na língua portuguesa como o conjunto de fatores psicológicos, de ordem fisiológica, intelectual ou afetiva, os quais, agindo em conjunto, determinam a atividade e a conduta do indivíduo (FERREIRA, 2006 apud ALMEIDA, 2012).

Em especial, no meio educacional, a motivação tem sido apontada como fator psicopedagógico que afeta diretamente o comportamento dos estudantes no meio escolar. Pesquisas têm avançado com a finalidade de investigar o impacto deste fenômeno na aprendizagem e no desenvolvimento educativo (GAGNÉ, 1985; GUIMARÃES; BORUCHOVITCH, 2004; MARINS; MOURÃO, 2007 apud GORDIANO et al., 2013). O tema é considerado importante, uma vez que o estudante necessita de motivação para se apropriar das experiências oportunizadas pelo ensino superior.
A motivação está presente em diferentes áreas da vida: no meio educacional, no social, na prática de esporte, no ambiente de trabalho, dentre outros. Assim, tratando especificamente do meio educacional, os estudantes do ensino superior enfrentam, com frequência, desafios que afetam o seu nível de motivação. Estes desafios estão associados a alguns fatores, como dúvidas com relação ao curso em que estão seguindo e o que pretendem fazer futuramente em sua profissão (GIL et al., 2012).

De acordo com Piletti (1997), a motivação é essencial para a aprendizagem, sendo, portanto, um fator fundamental. A ausência da motivação pode gerar uma queda na qualidade da aprendizagem. Desta forma, entende-se que quando apresenta um quadro de motivação adequado, o estudante tem melhores possibilidades de crescimento e pode alcançar mais sucesso na profissão.

De acordo com Todorov e Moreira (2005 apud Gil et al. 2012, p. 59):

A motivação tem sido entendida pelos teóricos como um fator psicológico, ou um conjunto de fatores e, ainda, como um processo. É responsável por uma escolha, pelo início de um comportamento que está direcionado a um objetivo e, além disso, assegura a persistência, apesar dos obstáculos.

Segundo Gil et al. (2012), renunciar a algo que no começo era desejável e agora parece muito sofrido ou difícil, talvez estabeleça a diferença entre o desejo de saber e a decisão de aprender. Aprender exige tempo e esforço, os quais dependem da motivação. Por sua vez, a desmotivação pode levar a sentimentos de angústia, fracasso, frustração, entre outros.

Conforme foi dito, motivação é como 
um impulso, um sentimento que faz com que as pessoas ajam para alcançar seus objetivos, é o que faz com que os indivíduos deem o melhor de si, façam o possível para conquistar o que desejam. Estudantes, profissionais ou pessoas que praticam esportes apresentam alguma motivação e, em sua ação, têm momentos com mais ou menos energia.

Assim, pode-se perguntar, qual seria o motivo que levaria a um comportamento mais ou menos motivado? É preciso observar nas atitudes e nas metas que dão motivo a esta ação. Tem-se como exemplo um estudante que realizará suas tarefas: ele pode estar fazendo por ser desprovido de curiosidade, ou pelo interesse de ser apenas aprovado, ou por estar motivado para adquirir novos conhecimentos para lhe trazer vantagens, também porque seus novos conhecimentos poderiam lhe dar notas boas.

Uma série de questões está relacionada à motivação dos estudantes acadêmicos, que pode ser provocada tanto por fatores internos como externos. "Uma definição geral do termo permite considerar como motivação o impulso suscitado por algum fator, podendo este impulso ser provocado por fatores externos ou internos" (ALMEIDA, 2012, p. 32).

Sendo assim, de acordo com a teoria da autodeterminação, a motivação pode ser distinguida em duas formas: intrínseca e extrínseca. Intrínseco é tudo que vem do próprio sujeito. "A motivação intrínseca abrange um comportamento mais autônomo, de causalidade interna" (GORDIANO et al., 2013, p. 5). É aquela que se origina da própria pessoa, como sua dedicação, sua competência e seu comprometimento para realizar alguma tarefa. Então a motivação intrínseca é aquela que não precisa de nenhum fator externo para obtê-la.
Em contraponto, o extrínseco é tudo que vem do meio. "A motivação extrínseca é regida por influência do ambiente social, ou por causa de contingências recompensadoras" (GORDIANO et al., 2013, p. 5). É aquela resultante de fatores externos, como os recursos de trabalho que o indivíduo recebe, o salário e o ambiente onde ele desenvolve suas tarefas.

As pessoas tendem a acreditar que as motivações intrínsecas são sempre positivas, enquanto as extrínsecas são sempre negativas, entretanto isso nem sempre é uma realidade. $\mathrm{O}$ fato é que elas atuam em conjunto e a resultante vai definir o comportamento do indivíduo no ambiente. Assim, os fatores motivacionais e afetivos têm relação direta com a aprendizagem dos alunos, de modo que o nível de desempenho e a motivação dos estudantes acadêmicos são avaliados de acordo com vários aspectos e atribuições internas e externas dos alunos.

De acordo com Sobral (2003), a teoria da autodeterminação aborda ainda um terceiro fator: a desmotivação. Esta, refere-se à ausência de qualquer motivação, intrínseca ou extrínseca. Desta forma, a teoria se completa com o grupo dos três tipos de motivação: intrínseca, extrínseca e desmotivação.

Muitos estudos sobre motivação já foram feitos, e autores identificam que a motivação e a afetividade em sala de aula são muito importantes. As interações entre professor e aluno, o que é valorizado em sala de aula, o clima psicológico, as estruturas de competição ou cooperação, entre muitas outras variáveis, podem estar relacionadas com o padrão motivacional do estudante (ALMEIDA, 2012). Quando o aluno se sente bem e à vontade na sua instituição de ensino, isso o faz querer estar presente nas atividades extras que ocorrem 
na universidade e também faz com que suas faltas nas aulas diminuam, fazendo com que ele aprenda cada vez mais durante a permanência no ambiente educacional.

Segundo Gil et al. (2012, p. 59):

Em sala de aula, a motivação implica em efeitos imediatos, como o envolvimento ativo nas tarefas do processo de aprendizagem. Sem ela, esse processo está, no mínimo, comprometido, já que representa uma queda no investimento pessoal, na qualidade e no desempenho das tarefas da aprendizagem.

A universidade em que o aluno está estudando também é um fator bastante considerável para que ele adquira motivação e conclua o curso nela iniciado. Segundo Gordiano et al. (2013), ao relacionar a qualidade do serviço educacional e a motivação acadêmica, intenciona-se apresentar resultados que indiquem que a qualidade do serviço educacional pode colaborar positivamente no resultado da aprendizagem dos alunos.

\section{METODOLOGIA}

O presente estudo é exploratório-descritivo com abordagem quantitativa. Foi utilizado como instrumento de pesquisa um questionário estruturado dividido em duas partes. A primeira parte apresenta a Escala de Motivação Acadêmica (EMA), oriunda da Academic Motivation Scale (AMS). Traduzida e validada no Brasil por Sobral (2003), a EMA é constituída de 28 itens. A segunda parte aborda as questões de natureza socioeconômica, que serviram para caracterização dos respondentes, tais como gênero, idade, estado civil e exercício de atividade remunerada. As questões foram aplicadas através de uma escala tipo Likert, de 10 pontos, onde 0 corresponde a "nada importante" e 10 corresponde a "muito importante".

A amostra é composta por 105 estudantes de dois cursos, Administração e Direito, de um Centro Universitário localizado na cidade de Fortaleza/CE. A aplicação dos questionários foi realizada no mês de abril de 2014, nos períodos da manhã e noite, nos semestres iniciais e finais de cada curso, por três pesquisadores, que deram instruções sobre como respondê-los. Não foi registrada nenhuma dificuldade por parte dos pesquisados quanto ao preenchimento do questionário.

Os dados foram trabalhados com auxílio do software SPSS (Statistical Package for the Social Sciences), versão 19.0, módulos de estatística descritiva, Análise de Médias e Análise de Variância (ANOVA).

\section{ANÁLISE DOS RESULTADOS}

A partir dos resultados da pesquisa, identifica-se que aproximadamente $43 \%$ dos alunos pesquisados são do sexo masculino e $54 \%$ do sexo feminino. Em relação à idade, 58\% dos alunos têm entre 18 e 22 anos, sendo a maioria solteira e sem filhos. Em relação à escolha do curso como primeira opção, aproximadamente $60 \%$ dos alunos afirmaram que o curso em que estão foi, sim, a primeira escolha.

Em relação a identificar qual o tipo de motivação que os alunos de cada curso apresentam, pode-se verificar os resultados no Gráfico 1. A motivação extrínseca, como é percebida, tem seus valores iguais para os dois cursos, sendo o tipo de motivação mais encontrada nos alunos, assentindo que 
as motivações externas têm um peso maior no dia a dia dos universitários. Apesar de mais complexo, foi percebido que mesmo que o índice do fator extrínseco seja maior, quando o universitário perde a motivação intrínseca, se torna mais vulnerável a se tornar desmotivado.

Ao realizar uma comparação direta entre o curso de Direito com o curso de Administração, tem-se que: $44 \%$ dos alunos do Direito estão motivados intrinsecamente e $8 \%$ estão desmotivados, enquanto na Administração se observa $43 \%$ da motivação intrínseca e 9\% de desmotivação. Os dois cursos apresentaram 48\% na motivação extrínseca (Gráfico 1).
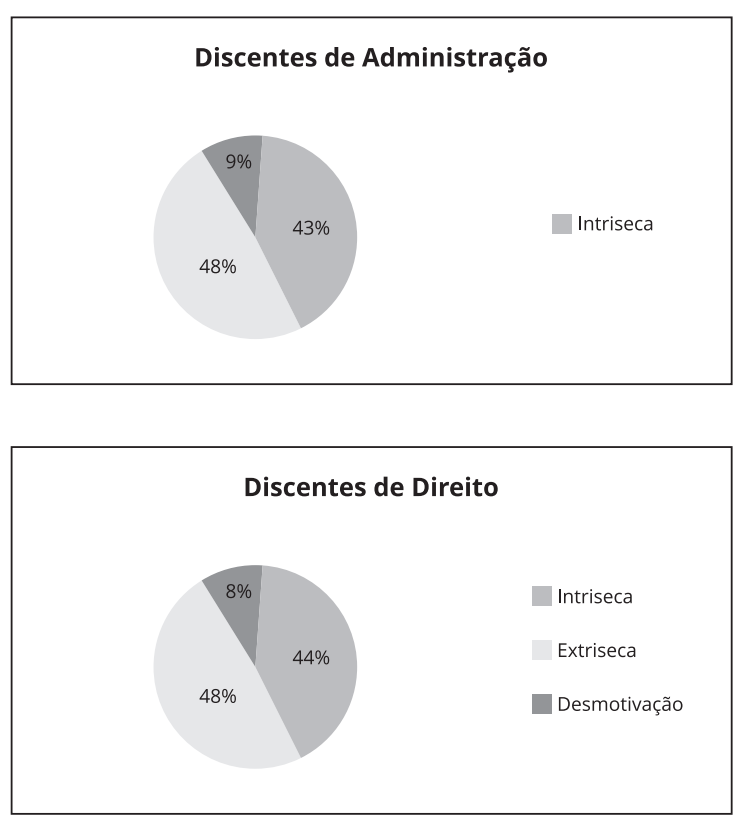

Gráfico 1 - Motivação Intrínseca, Extrínseca e Desmotivação

Fonte: dados da pesquisa (2014)

Em relação à comparação por turno, apresenta-se na Tabela 1 o resultado do curso de Administração. Foi percebido que os discentes de Administração do turno da manhã têm sua motivação extrínseca mais alta do que os alunos da noite, com a diferença aproximada de 1,7. Em relação à motivação intrínseca, se demonstrou uma diferença mais elevada, de aproximadamente 2,38. Este resultado constata que os universitários da manhã estão mais motivados que os universitários da noite. Em relação à desmotivação, os alunos de Administração de ambos os turnos apresentaram médias bem baixas, sendo aproximadamente 1,38 para o turno da manhã e 1,55 para o turno da noite.

Para saber se existe diferença significativa entre essas médias, foi realizado o teste de diferença entre médias de grupos - ANOVA. A motivação intrínseca e a motivação extrínseca apresentaram, respectivamente, os seguintes resultados: $\mathrm{F}=21,35$ e $\alpha=0,000 ; \mathrm{F}=8,418$ e $\alpha=0,007$ (Tabela 1). Esses dados demonstram que a diferença entre essas médias são significativas, corroborando o que já foi explanado. Em relação à desmotivação, os valores $\mathrm{F}=0,62$ e $\alpha=0,805$ confirmam que não existe diferença significativa em relação aos turnos pesquisados.

Tabela 1 - Curso de Administração por turno

\begin{tabular}{|l|r|r|r|r|}
\hline & \multicolumn{2}{|c|}{ Médias } & \multicolumn{2}{c|}{ ANOVA } \\
\hline & Manhã & Noite & \multicolumn{1}{c|}{ F } & Sig. \\
\hline Motivação & & & & \\
\hline Intrínseca & 7.8958 & 5.5167 & 21.354 & .000 \\
\hline Extrínseca & 8.3114 & 6.6136 & 8.418 & .007 \\
\hline Desmotivação & 1.3750 & 1.5455 & .062 & .805 \\
\hline
\end{tabular}

Fonte: dados da pesquisa (2014)

No curso de Direito, a diferença de média encontrada nas motivações intrínseca e extrínseca foi muito pequena, apresentando um nível de motivação análogo. Ao analisar os valores do teste ANOVA: $\mathrm{F}=$ 
0,600 e $\alpha=0,442 ; \mathrm{F}=1,607$ e $\alpha=0,209$, respectivamente para intrínseca e extrínseca, pode-se confirmar que não existe diferença significativa das médias dos dois turnos, como é possível observar na Tabela 2.

Um bom resultado encontrado refere-se à desmotivação no turno da noite com média aproximada de 0,8. Embora o valor encontrado referente ao turno da manhã também tenha sido baixo $(1,7576)$, com os dados do teste ANOVA pode-se inferir que existe diferença significativa entre os turnos. Desta forma, os alunos do turno da noite são os que menos estão desmotivados (TABELA 2).

Tabela 2 - Curso de Direito por turno

\begin{tabular}{|l|r|r|r|r|}
\hline & \multicolumn{2}{|c|}{ Médias } & \multicolumn{2}{c|}{ ANOVA } \\
\hline & Manhã & Noite & \multicolumn{1}{c|}{ F } & \multicolumn{1}{c|}{ Sig. } \\
\hline Motivação & & & & \\
\hline Intrínseca & 6.5417 & 6.8922 & .600 & .442 \\
\hline Extrínseca & 7.6875 & 7.2548 & 1.607 & .209 \\
\hline Desmotivação & 1.7576 & .8041 & 4.513 & .037 \\
\hline
\end{tabular}

Fonte: dados da pesquisa (2014)

Continuando a investigação entre os cursos, procedeu-se ainda a comparação das médias por semestres, dividindo-os em dois grupos: semestres iniciais (primeiro ao quarto) e semestres finais (quinto ao oitavo). Conforme os dados apresentados na Tabela 3, os resultados das motivações intrínsecas e extrínsecas foram opostos ao comparar os dois cursos. No curso de Administração, os alunos dos semestres iniciais possuem maior média na motivação extrínseca e os dos semestres finais possuem maior média na motivação intrínseca. Já no curso de Direito, os alunos que estão mais perto de se formar possuem maior média na motivação extrínseca, enquanto que os dos semestres iniciais possuem maior média na motiva- ção intrínseca.

Acredita-se que este resultado divergente pode estar relacionado com o perfil profissional de cada curso, pois demonstra que mais perto da formatura a motivação do aluno do Direito tende a estar mais relacionada a questões profissionais e de recebimento do diploma. Em contraponto, o aluno da Administração dos semestres finais está mais motivado por questões de realizações pessoais.

Em relação à desmotivação, os dois cursos apresentaram maior média nos semestres inicias, de acordo com os dados da Tabela 3. Desta forma, fica evidente que os alunos dos semestres finais, por estarem mais perto de concluir o curso e se formarem, estão mais motivados a terminá-lo.

\begin{tabular}{l} 
Tabela 3 - Médias de Motivação por \\
semestre \\
\hline \\
\hline
\end{tabular}

Fonte: dados da pesquisa (2014)

Em relação ao grau de motivação global para prosseguir com os estudos, pode-se observar na Tabela 4 que as médias encontradas nos dois cursos foram bem elevadas. Ressalta-se que nesta questão os alunos informavam livremente o quanto estavam motivados, dando valor de $0 \%$ a 100\%. No curso de Administração, percebe-se que os alunos do turno da manhã se consideram mais motivados. Esta diferença entre os turnos é significativa, comprovada pelo teste ANOVA com $F=12,112$ e $\alpha$ 
$=0,002$. Em relação ao curso de Direito, a motivação dos alunos se mostrou quase igualitária entre os dois turnos, sendo percebida um pouco mais no turno da noite.

Tabela 4 - Grau de motivação global para prosseguir nos estudos e se formar

\begin{tabular}{|l|r|r|c|c|}
\hline & \multicolumn{2}{|c|}{ Turno } & \multicolumn{2}{c|}{ ANOVA } \\
\hline & Manhã & Noite & F & Sig. \\
\hline $\begin{array}{l}\text { Motivação global } \\
\text { Administração }\end{array}$ & 92.65 & 74.78 & 12.112 & .002 \\
\hline $\begin{array}{l}\text { Motivação global } \\
\text { Direito }\end{array}$ & 82.67 & 89.77 & 3.456 & .068 \\
\hline
\end{tabular}

Fonte: dados da pesquisa (2014)

\section{CONSIDERAÇÕES FINAIS}

A partir dos dados obtidos, pode-se atingir o objetivo proposto neste estudo que era identificar a motivação para aprendizagem dos discentes de Administração e Direito de um Centro Universitário em Fortaleza-Ce e as possíveis diferenças em razão dos cursos e turnos dos alunos. Foi possível comparar os dois cursos em questão e seus turnos (manhã e noite), e identificar a motivação extrínseca e intrínseca, e desmotivação de cada um. Percebeu-se que neste estudo as motivações dos discentes são bastante elevadas e equivalentes, tanto entre si, como comparadas às duas graduações.

Pode-se então considerar que a motivação dos universitários pode ser intrínseca e extrínseca, e que apesar do tamanho desta amostra, percebeu-se que a motivação pode ser diferente dentro da mesma instituição, variando de acordo com o turno. Nesta pesquisa viu-se que na Administração os alunos do turno da manhã são mais motivados do que os da noite. No curso de Direto, a pequena diferença não é representativa, o que se infere que os alunos dos dois turnos possuem o mesmo nível de motivação.

Em relação à desmotivação, os resultados se invertem. Os alunos de Administração dos dois turnos não apresentaram diferença significativa entre as médias. Já os alunos de Direito do turno da noite apresentaram uma menor desmotivação que os da manhã. Cabe ressaltar que todas as médias de desmotivação foram muito baixas, sendo a maior delas 1,75. Este dado é importante, pois se pode aferir que, de uma forma geral, a amostra pesquisada encontra-se bastante motivada em seu curso.

$O$ resultado deste estudo não pode ser generalizado, mas é de grande importância para a instituição, funcionando como um feedback. Os dados podem ser utilizados para análise e viabilização de uma solução plausível para obter um índice de motivação ainda maior. Ao analisar o comportamento do aluno em relação a sua motivação, pode apresentar um bom instrumento para a gestão da universidade. Contribui, ainda, com a área acadêmica, ao utilizar a escala EMA e fomentar as discussões acerca de motivação estudantil.

Sugere-se a continuidade deste estudo, com a ampliação do universo da amostra para abranger todos os cursos dentro da mesma instituição e ainda a repetição da pesquisa em momentos posteriores com os mesmos cursos, intencionando identificar se existe variação na motivação dos estudantes. Estas pesquisas podem ser feitas de forma sistemática, tornando-se uma forma validada de se avaliar a instituição e envolver os gestores e os professores na busca da constante motivação dos alunos. Sugere-se ainda a aplicação deste estudo em diferentes instituições privadas e públicas.

Por fim, sugere-se um aprofundamento deste estudo, analisando em conjun- 
to com a motivação do aluno, constructos de percepção da qualidade. Desta forma, o confronto de pesquisas no mesmo tema e relacionados à qualidade do ensino propicia a formação de conhecimentos empíricos para auxiliar a gestão empresarial das instituições, além de identificar similaridades e diferenças no setor educacional.

\section{MOTIVATION IN UNIVERSITY COURSES: A STUDY WITH THE STUDENTS OF THE COURSES OF MANAGEMENT AND LAW}

\section{SUMMARY}

Thestudent'smotivationisoneoftheessential components for learning. According to the theory of self-determination, that motivation can be intrinsic and extrinsic and its absence generates demotivation. The aim of this paper work is to identify the motivation for learning of the students of Administration and Law of a University Center in Fortaleza-Ce and the possible differences in terms of the courses, the students' day periods and semesters. In order to reach a reasonable result, a quantitative research was carried out using as research instrument a questionnaire adapted and validated for higher education by Sobral (2003). The scale which was employed uses the constructs of extrinsic and intrinsic motivation and the attitudes of demotivation. The sample resulted in 105 valid questionnaires. The analysis of the data showed that the students of both courses are motivated by intrinsic and extrinsic factors, and that there are differences among the turns or day periods of study in the Course of Administration.
Keywords: Motivation. Higher Education. Administration. Law.

\section{REFERÊNCIAS}

ALMEIDA, D. M. S. A motivação do aluno no ensino superior: um estudo exploratório. 2012. 149f. Dissertação (Mestrado Educação) - Universidade Estadual de Londrina, Paraná, 2012. Disponível m: $<$ http:// www.uel.br/pos/mestredu/images/stories/ downloads/dissertacoes/

2012/2012_-_ALMEIDA_Debora_Menegazzo_Sousa.pdf $>$. Acesso em: 05 abr. 2014.

GIL, E. S. et al. Estratégias de ensino e motivação de estudantes no ensino superior. Vita et Sanitas, Trindade-Go, n. 6, p. 57-81, jan./dez. de 2012. Disponível em:< http://fug.edu.br/revista_6/pdf/artigo4. pdf $>$. Acesso em: 10 abr. 2014.

GORDIANO, E. C. S. et al. A percepção do cliente: qualidade na educação superior e motivação discente. In : Seminário em administração - SemeAd , 16., 2013, São Paulo. Anais... São Paulo: FEA- USP, 2013. Disponível em: <http://semead6.tempsite. ws/16semead/resultado/trabalhospdf/882. pdf $>$. Acesso em: 05 abr. 2014.

GUIMARÃES，S.É.R.; BORUCHOVITCH, E. O Estilo Motivacional do Professor e a Motivação Intrínseca dos estudantes: uma Perspectiva da Teoria da Autodeterminação. Psicologia Reflexão e Crítica, Rio Grande do Sul, v.17, n.2, p.143-150, 2004. 
JOLY, M. C. R. A.; PRATES, E. A. R. Avaliação da Escala de Motivação Acadêmica em estudantes paulistas: propriedades psicométricas, Psico-USF, Itatiba, v. 16, n. 2, p. 175-184, 2011.

MATHIAS, J. F. C. M. Breves Considerações sobre a Evolução do Ensino Superior do Brasil no Período Recente, Revista CADE-FMJ, v.10, p.169-180, 2004.

PILETTI, N. Psicologia educacional. São Paulo: Ática, 1997.

SILVA FILHO, R.L.L.; MOTEJUNAS P. R.; HIPÓlitO O.; LOBO, M.B.C.M. A Evasão No Ensino Superior Brasileiro. Cadernos de pesquisa, São Paulo, v.37, n.132, p. 641-659, set./dez. 2007.

SOBRAL, D. T. Motivação do aprendiz de Medicina: uso da escala de motivação acadêmica, Psicologiateoria e Pesquisa, Brasília, v.19, n.1, p. 25-31, jan./abr. 2003. 